\title{
SERMÓN DEL TIEMPO. EL ORFEBRE EN EL TEMPLO DEL OÍDO
}

Sobre Santiago Hernández Aparicio. Sermón del tiempo. Rosario: Baltasara, 2017, 94 pp.

Tomás Sufotinsky

UNR

\section{La lectura como trabajo}

Sermón del tiempo es el primer libro de poemas publicado por Santiago Hernández Aparicio. Se trata de un texto dividido en cinco secciones, cada una compuesta por siete poemas (número que atraviesa todo el contenido de la obra). A su vez, el libro está antecedido por un "Proemio" del autor y acompañado por un riguroso "Epílogo" escrito por Héctor Piccoli, el cual constituye una meticulosa exégesis de los temas centrales tratados por Santiago.

Sermón del tiempo es, y de ello nos enteramos apenas abrimos el libro, el fruto de cinco años (2010-2015) de un trabajo poético. ¿Por qué el énfasis en estas palabras? -Nunca la escritura de poesía, es sabido, se trata de la mera redacción inmediata de textos que van "surgiendo" a la imaginación, pero no son muchas las veces en que un conjunto de textos poéticos evidencian como aquí la puesta en práctica de las herramientas, materiales y recursos que hacen de la poesía un trabajo específico. Pues, si el pintor debe conocer cómo interactúan los colores entre sí y si el músico debe conocer las leyes que unen a las notas de una escala, es evidente que el poeta debe conocer, asimismo, el material con el que trabaja. 
Y tal es el caso de este libro: un trabajo poético llevado a cabo a lo largo de un quinquenio, que acompañó a su vez a otro trabajo realizado sobre la poesía, dedicado a su lectura y su estudio, como ocupación del autor. Piccoli, en su epílogo "Sermón del tiempo: una crisopeya insular", se remite, al respecto de esto, a la clásica fórmula heideggeriana "poetizar-pensante" y su inversión "pensar-poetizante". Pues, como el poeta de Hölderlin (autor fundamental para esta obra) recibe el rayo del Padre y -una vez aplacado en su pecho- devuelve la canción, se trata aquí de un trabajo de elaboración, de fagocitación de una cultura internalizada y de meditaciones realizadas al respecto de ella que son devueltas y sustentadas por las técnicas que permitan el enaltecimiento de estos pensamientos en un cogollo a florecer tras los ojos del lector. Es que, al decir de Mallarmé: "nombrar un objeto supone eliminar las tres cuartas partes del placer que nos ofrece un poema que consiste en adivinar poco a poco; sugerirlo, éste es el camino de la ensoñación”.

¿Y cuáles son estas técnicas? La alusión, por supuesto, cuando el autor se refiere, por ejemplo, en "Composición sin marco" al crepúsculo en los siguientes términos:

"un rosa pálido enalteció la sombra"

Aunque tampoco hesita el verso en cargar toda su fuerza en la propia palabra:

"Se llama terror la concavidad oscura/ que me ciega cuando digo el nombre del oro" (Espíritu del tiempo)

Pero tal vez donde resida el mayor tesoro retórico del libro sea en el trabajo de sustituciones que implica ese arco que va de la comparación a la metáfora pura, pasando por la impura, con su poder de definición: 
Ni Rusia otoñal, ni plaza sangrienta, donde aterradoras musas gritan y la mano, sismógrafo marchito, tiembla y vuela como corza herida.

ahí no nací yo: sí en las montañas, planicies por la carga amodorrada de provincias con el paso de fantasma (Anonimato en la montaña)

Los corazones son bruma en tiempos en que la guerra impone su escalofrío y su sordina sobre el coral vetusto del día (El emblema del huérfano)

Asimismo, podría perderse uno vagando por la proliferación de los oxímoron e hipérbatos que enriquecen al libro, por recordar uno sólo:

y el reloj al costado de la cama

mide $\left[\right.$ del sueño $2^{\circ}$ [el tiempo $] 1^{\circ}[$ al revés $] 3^{\circ}$. (La vuelta) (Se entrelazan aquí forma y contenido, potenciándose)

Pero no se trata por todo esto, como podría pensar algún oído actual, de una poesía anacrónica. Nada menos anacrónico que el Tiempo, centro mismo de esta obra o acaso voz misma de ella (¿será acaso quien pronuncia el sermón? me pregunto); nada más persistente que el recuerdo, el infantil, el de las 
personas a quienes perdimos (como en Ofrenda a Juan Pablo, o cuando se dice "La carta abre/ el ventanal./ El recuerdo pájaro"); nada más acuciante aún hoy que nuestra fascinación por lo animal frente a la indigencia de nuestra percepción ("Un haz de luz/ abraza al benteveo./ Ventana ciega"); nada más constante y presente que el "Fatal, irrevocable fracaso en la materia/ [que] apenas deja tiempo, aire a la bocanada" y "...Atenas: dulce muerte/ de lo que es amado a medias. La materia/ no se rebela contra la materia, es claro.../ Y el destello del alma, ¿dice adiós desde dónde?”.

Este libro, que indaga sobre el Tiempo -y por ello también admite la pregunta por el que se fue y se deja de ser todo el tiempo, es decir por el crecer-, indaga poéticamente, como las investigaciones de un niño: puro presente ("Un niño, pensado siempre desde la futuridad, es en realidad puro presente, y de alguna forma, sabe hablar la muerte, porque sólo el niño es capaz de engendrar un pensamiento que nos destruya, que transgreda la finalidad del demiurgo", no del autor a "El espectro de Polidoro"). Es el trabajo de la poesía como un texto que está sucediendo en el acto de su lectura, en la comunión o en la crisopeya que se da entre el poema y su lector. Por eso es un libro también acerca de la poesía misma como patria de un pensamiento trascendente.

La lectura de Sermón del tiempo nos pone, entonces, en el lugar de realizar un trabajo que, si bien nos facilita con sus notas aclaratorias, no deja de ser un trabajo para el que hay que disponerse con las armas que uno posea y del que seguramente se saldrá enriquecido en el arsenal. Implica un disponerse a indagar en las intertextualidades y referencias, pero, sobre todo y antes que nada, disponerse a esa maravillosa pausa en la que uno, lector, levanta la vista del libro y busca en la abstracción de la ventana o de la pared que esas palabras que quedaron 
resonando conjuren la imagen del entendimiento, racional y sensitivo.

\section{Los ecos que resuenan en el templo del oído: La estructura del libro.}

Una trama de temas cohesiona la obra "enhebrando eco con eco" ("Rincón-Isla Verde-Rosario") en una armonía que teje los vínculos anularmente entre los capítulos y al interior de cada uno de ellos, como sugieren ciertas correspondencias léxicas en los títulos a la primera vista del índice. Existe, entonces, un doble índice: el tradicional, en el que se realiza una lectura progresiva del libro, y uno alternativo, en el que el primer poema de cada sección remite al último, el segundo al anteúltimo, el tercero al antepenúltimo y el del medio pareciera transportarnos, en este mismo sentido, a su capítulo paralelo. Así, "La ronda del deseo" en la sección homónima, la primera, nos transporta al poema "En el ojo de este huracán" en la sección última, En el teatro del ojo. Cada segmento lleva al centro de su segmento paralelo y al transitar esta lectura terminamos en el núcleo del libro, Ofertorio, en el que se condensan los temas que ocupan a los anillos que lo envuelven.

Pero es, en mi opinión, en el transitar esta doble lectura del libro, o bien, en las lecturas de los dos libros -aquella en la que avanzamos progresivamente de principio a fin saltando en el medio del libro al interior de una especie de espejo que nos devuelve, finalmente, al principio, y la otra, la anular, en la que saltamos de principio a fin en $y$ entre las secciones acercándonos al núcleo del libro-, es en esta doble lectura que verdaderamente logramos apreciar la riqueza constructiva de Sermón del tiempo.

Son estos, entonces, los sistemas de ecos que estructuran al libro de Santiago. Pero hay, además, otra serie de ecos entre 
poemas, ecos más aleatorios, que van rebotando a lo largo de las lecturas, discutiendo temas como la muerte ("Ofrenda a Juan Pablo" y "Plaga con atomista"), la dilucidación del tiempo ("La mirada fija en el llano" y "Un encierro transparente"), las figuraciones de lo extraño [das Unheimliche], como en la segunda parte del poema "Sueño en la nieve":

El duendecito me había gritado al oído

algo tan lejano y tan familiar

- esa es la rosa mariana del asunto, que en sueños se tornó un animal horroroso:

algo inmenso, pesado e infinitamente descomponible que nadaba sobre mí-.

O en "Composición sin marco", donde se dice: "se aloja en tu mundo un animal extraño".

De la misma manera, algunos elementos van sellando a lo largo del libro sus roles simbólicos: la luna, por ejemplo, en diversos lugares, como "Filiación del pequeño":

La luna helada tiembla

- dijo el pequeño-

y revuelve lo que en mí duerme.

¡Arrastra, arrástrame en septiembre!

Levanta ya la máscara de tu palidez obtusa.

Llevo y traes lo que entre nosotros acaece, nadie ve nuestro oscuro encuentro en la montaña. 
En respuesta, expiras sacramente

desdibujando lo que queda de mi esbozo

de claridad letal para la aurora.

En "Mientras camina bajo la lluvia...":

$\mathrm{Ni}$ vidrios animados sin deseo, transverberados por fulgor lunar, ni ángeles que en fruncida gravedad la unidad fulguran de lo abierto, nada de eso somos en la tierra:

O en "Composición borroneada":

ya ardía el fuego en Ifigenia ardió demasiado en las cenizas, proceso que se quedó sin pira, luna aguada que sacudió el ánimo.

Así como también se forman paralelismos con respecto a la meditación acerca de la experiencia adulta del tiempo, en "Espíritu del tiempo":

Instante oscuro, Tiempo luminoso, mis dos hermanos muertos:

nada tengo que ofrendarles, ni silencio ni música, 
y la memoria lo es sólo de lo que pasa, тò $\alpha \pi \circ \theta v \tilde{\eta} \sigma \varkappa \varepsilon \iota \nu$ xaxóv ${ }^{1 .}$

Y la infantil, en "El espectro de Polidoro", a cuya nota al pié ya nos referimos:

ah, nosotros, sólo vemos el reservorio de esperanza, somos los clarividentes del instante.

Por otro lado, o para tan sólo nombrar uno más, también el tópico mitológico de Diana, la cazadora, atraviesa implícita o explícitamente varios poemas ("Ofrenda a Juan Pablo", "Composición borroneada", "La mirada fija en el llano").

Pero además de los ecos que ya mencionamos que llegan desde Hölderlin y, principalmente el himno IV de Calímaco (la rosa desbordada en el núcleo de este libro), también resulta evidente la voz de Rilke resonando a lo largo de los poemas, en la figura de ángel, por ejemplo:

Paisaje, hipótesis que vendrá

a refutar el tiempo, ese fantasma

que pliega el plano austero

de la visión de un hombre

en los mil mundos

en la retina de un ángel?

1 tò apothnéskein kakón ("morir es malo"), segmento del corpus de Safo, llegado a nosotros por transmisión indirecta (Aristóteles, Retórica, II. 23, 1398 b). Completo, dice "morir es malo y los dioses así lo juzgan, pues si no morirían". 
la mención de "lo abierto":

ni ángeles que en fruncida gravedad

la unidad fulguran de lo abierto,

nada de eso somos en la tierra:

Aunque también en el tratamiento de la animalidad, y hasta en citas furtivas: "el templo del oído" se dice en "Sueño en la nieve" citando al primero de los sonetos a Orfeo.

Finalmente, creo que cabe decir aún algo más acerca de esta lectura anular alternativa a la lectura progresiva, y es que, entramándose con las meditaciones acerca del Tiempo, "esa es la rosa mariana del asunto", esta estructuración parece dar forma a una refutación de su percepción tradicional y a la instauración de un Tiempo mayor, en que no solamente los extremos se tocan, otra vez:
Paisaje, hipótesis que vendrá
a refutar el tiempo, ese fantasma
que pliega el plano austero
de la visión de un hombre
en los mil mundos
en la retina de un ángel?

Sino que también existe un núcleo desde el que todo desborda: 
“¿Quién colocó

una rosa desbordada

en el núcleo de la luz?” (A Septiembre, en el núcleo exacto del libro)

\section{La lectura como escucha}

La circularidad atraviesa todo el Sermón del tiempo. Ya se habló de su estructura anular de círculos concéntricos hacia un núcleo, pero las referencias y las alusiones a lo circular proliferan a lo largo del libro, y en más de un plano. En primer lugar, podríamos relevar fácilmente la cantidad de veces en que aparece nombrado el "círculo" mismo y elementos que remitan a él, como el "ojo", la "corona", el "anillo" y la "ronda", por nombrar algunos ejemplos. Pero también encontramos imágenes que pueden ser tomadas como alusiones a la circularidad, como en el último verso del soneto "La vuelta": "que quien se sabe ir sabe volver", o "Alegoría de qué tu abrazo" y "enhebrando eco con eco" en "Rincón-Isla VerdeRosario", también en las referencias a la danza como "¿Dice algo todo esto, este bailar y bailar/ sin rumbo?" en "Livets dans", y "la danza concéntrica del coro" en "La mirada fija en el llano".

¿Pero qué es lo que nos llama la atención, en definitiva, de lo circular?, ¿será, acaso, la sugerencia de algo que obtiene un cierre, que se sella: "nos tomamos las manos/ para cerrar algunos círculos. Ese es nuestro sello." (Espíritu del tiempo) o, por el contrario, la idea de un movimiento vano? -En todo caso, existe algo de hipnótico en la idea del movimiento circular, algo como un conjuro, y, si se me permite aún otra pregunta ¿qué es lo que conjura la poesía?, y ¿qué es lo que en la poesía opera como conjuro? -"Espíritu del tiempo" comienza diciendo "Se llama terror la concavidad oscura/ que 
me ciega cuando digo el nombre del oro.", pero como ya sabemos lo que no se quiere decir, de alguna manera termina emergiendo en el discurso, termina siendo conjurado en la lengua. Y esto nos remite a último plano y el más sugerente al respecto de la circularidad: la música. Ella está absolutamente presente en la obra, tanto en sus menciones y alusiones como en su presencia misma, fónica, que toma su lugar en la poesía principalmente en la forma del ritmo, la rima y la aliteración: ese fenómeno que nos hipnotiza de un poema aunque en un inicio no comprendamos por medio de la razón, (¿quién podría decir, tras su primera lectura, algo con certeza acerca de los versos "LANCES DEL MAL SON/ LINCES QUE DEL MAL/ LAMEN LA MANO" de Aldo Oliva en el poema "Aldebarán"? y sin embargo ¿no nos cautivan con su música?). Escuchemos cómo funciona esto en algunos fragmentos del Sermón...

(El nombre del mar)

Pero también viven fantasmas en eso que se llama tiempo,

hay otras islas donde nacen los cegados por Apolo,

islas móviles en busca de un hogar

por cualquier lado, de un jardín

en medio del mar, donde las diosas

los llamen con la médula de la lengua,

donde el nombre del mar coincida con su nombre.

(Un encierro transparente)

Paisaje, hipótesis que vendrá

a refutar el tiempo, ese fantasma 
que pliega el plano austero

de la visión de un hombre

en los mil mundos

en la retina de un ángel?

Sin flor, sin libro, sin tordo ni luz, ...

(Un manto que diga NUNCA)

mil sílabas lanzadas con humildad hacia la nada, mil sílabas al amor apagado, a las fiestas infantiles de extraviados souvenires...

(Ofrenda a Juan Pablo)

Celoso protector que desplegabas

pistas para el pájaro canoro,

Pero adquiere incluso aún más importancia fonética aquel sonido donde se explicita y se dibuja el círculo:

(Livets dans)

A veces desearía que la mujer

del vestido rojo me dijera dónde hay oro, dónde hay oro en todo esto.

(Espíritu del tiempo)

Se llama terror la concavidad oscura

que me ciega cuando digo el nombre del oro. 
No sería osado arriesgar que la vocal $\mathrm{O}$ aparece en toda la obra como la nota tónica de la armonía que la gobierna. Porta el nombre del oro, es la diana donde acertó el flechazo de Apolo (figura alrededor de la cual gira la obra), la rosa desbordada en el núcleo de la luz, el círculo cerrado por el fuego del cielo y la calma del hombre a que se hace referencia en la carta a Böhlendorff de Hölderlin, fechada el día de su muerte (cerrando del ciclo de su vida), que abre la sección "Negro sobre blanco".

Quisiera, en este sentido, terminar con un poema, por otra parte ya mencionado que, si se me permite utilizar la jerga musical, contempla todo lo que concierne a la textura (la combinación de los materiales rítmicos, armónicos y melódicos): "La vuelta", soneto en que el lector puede, a primera lectura, distenderse del trabajo intelectual de la interpretación y dejarse resbalar por sus versos oyendo la pura música en el poema:

¡Fiesta de la coronación, les digo

cuando la erosión de la memoria

falle, de los objetos la victoria

el día en que floten sin testigos!

Se congregan las flores en corona, ya no las toca el corazón marchito, hasta la atrocidad de nebulosas cae, cercana y tierna en este sitio.

Desde los sauces vuela la torcaza, 
ya no recuerda qué hace después,

y el reloj al costado de la cama

mide del sueño el tiempo al revés.

Corona de oro en cabeza cortada, que quien se sabe ir sabe volver. 